Research Article

\title{
Online Simulation of Nuclear Power Plant Primary Systems
}

\author{
Hongyun Xie $\mathbb{D}^{D}$, Haixia Gu $(\mathbb{D}$, Chao Lu $\mathbb{D}$, and Jialin Ping $\mathbb{1}$ \\ State Key Laboratory of Nuclear Power Safety Monitoring Technology and Equipment, \\ China Nuclear Power Engineering Co., Ltd., Shenzhen, Guangdong, China \\ Correspondence should be addressed to Hongyun Xie; xiehongyun@cgnpc.com.cn
}

Received 23 June 2020; Revised 16 October 2020; Accepted 30 November 2020; Published 15 December 2020

Academic Editor: Guglielmo Lomonaco

Copyright (C) 2020 Hongyun Xie et al. This is an open access article distributed under the Creative Commons Attribution License, which permits unrestricted use, distribution, and reproduction in any medium, provided the original work is properly cited.

\begin{abstract}
Real-time Simulation (RTS) has long been used in the nuclear power industry for operator training and engineering purposes. And, online simulation (OLS) is based on RTS and with connection to the plant information system to acquire the measurement data in real time for calibrating the simulation models and following plant operation, for the purpose of analyzing plant events and providing indicative signs of malfunctioning. OLS has been applied in certain industries to improve safety and efficiency. However, it is new to the nuclear power industry. A research project was initiated to implement OLS to assist operators in certain critical nuclear power plant (NPP) operations to avoid faulty conditions. OLS models were developed to simulate the reactor core physics and reactor/steam generator thermal hydraulics in real time, with boundary conditions acquired from plant information system, synchronized in real time. The OLS models then were running in parallel with recorded plant events to validate the models, and the results are presented.
\end{abstract}

\section{Introduction}

Real-time simulation (RTS) has long been used in the nuclear power industry for operator training and engineering purposes. The applications of RTS, however, are usually isolated from the real plant operations and information systems. With the advance of computer and information technologies, efforts have been made to connect the RTS with the plant operating database, to enhance the efficiency and safety of the nuclear power plants (NPPs). Online simulation (OLS) is defined as this connection of RTS and the plant information system to acquire the measurement data in real time for calibrating the simulation models to follow plant operations for the purpose of analyzing plant events and providing indicative signs of malfunctioning.

The OLS is nothing new in theory and application for process industries, like coal-fired power stations, steel, cement, and oil and gas pipelines. It is expected that the OLS can improve the safety and efficiency of these processes. For example, the OLS developed by ASC in China has been applied in the $500 \mathrm{MW}$ coal-fired unit of Huaneng Yimin Power Plant to save coal consumption, reduce emission, and optimize power production [1]. In the oil and gas industry, OLS has been used to optimize pipeline transportation. Italy's Snamprogetti, S.p.A., has developed a dispatching tutorial system specially used for gas pipeline network. The software can be operated in OLS mode or offline mode through SCADA system interface software. Transportation algorithm's formulation, control, and optimization can be carried out online, and training can be conducted offline [2]. The OLS was also applied to the deep learning of an AI system for nuclear power plant transient analyses [3]. However, the application of OLS in the nuclear industry to support nuclear power plant operation is rare. The only OLS application of such kind is the core monitoring systems, like the Westinghouse's BEACON [4] and the Framatome ANP's US3D [5], to monitor the thermal margins of the nuclear reactor core during power maneuvering. One of the reasons was lacking accurate model which can be solved in real time. Recent years, with the advancement of computer technologies, high fidelity engineering grade 
models running in real time becomes a reality. A research project, the first of its kind, as part of the China General Nuclear's (CGN's) Intelligent Nuclear Power Plant initiative, is to apply the OLS to develop a system for the main control room to assist NPP operators during critical operations to avoid faulty conditions and therefore ensure safety and efficiency of the NPP.

An NPP consists of many systems and equipment and involves areas of thermal hydraulic, reactor core physics, mechanical engineering, instrumentation, controls, etc. Realizing the OLS on the entire NPP, at current time, is not feasible. Therefore, the current stage of the research project is to focus the applications of OLS on certain critical operations of reactor core and reactor/steam generator flow circuits of a CGN CPR1000 NPP. The OLS models have been developed for the reactor core physics and reactor/steam generator thermal hydraulics based on the referenced plant's RTS models, which are executed and synchronized in real time, with boundary conditions acquired from plant information system.

The referenced CPR1000 NPP is a 1000 MWe 3-loop PWR unit located in Guangdong Province, China, and has been in operation since 2014. The unit's control room is equipped with modern digital control systems. One of the digital control systems is a plant data acquisition and monitoring system, KNS, which is monitoring and recording all plant transmitter signals as well as performance data, in real time. The OLS system, as presented in this paper, is based on a digital I\&C validation real-time simulation platform (Figure 1) in the State Key Laboratory of Nuclear Power Safety Monitoring Technology and Equipment of China Nuclear Power Engineering Co., Ltd., located in Shenzhen, Guangdong, China.

This paper presents the results from a stage of the OLS research project to validate the fidelity of the OLS simulation models. It describes the methodologies of the simulation models and their inputs and outputs. The inputs to the simulation models are the boundary conditions of the OLS models, and they are obtained from sets of KNS historical data which were collected from the referenced plant for each plant event used for the validation. The calculated results of the OLS models were compared with the corresponding KNS historical data to validate the use of these simulation models for further development of OLS applications to support plant operations.

\section{Simulation Models}

2.1. Reactor Core. The real-time reactor core model of the digital I\&C validation platform is a three-dimensional, two energy group, kinetics model based on the time-dependent neutron diffusion equations and the delayed neutron precursor balance equations [6]:

$$
\begin{aligned}
\frac{1}{v_{1}} \frac{\partial \varphi_{1}(\underline{r}, t)}{\partial t}= & \nabla \cdot D_{1}(\underline{r}, t) \nabla \varphi_{1}(\underline{r}, t)-\Sigma_{1 \longrightarrow 2}(\underline{r}, t) \varphi_{1}(\underline{r}, t) \\
& -\Sigma_{a, 1}(\underline{r}, t) \varphi_{1}(\underline{r}, t)+(1-\beta) \\
& \cdot \sum_{g=1}^{2} v \Sigma_{f, g}(\underline{r}, t) \varphi_{g}(\underline{r}, t) \\
& +\sum_{k=1}^{6} \lambda_{k} C_{k}(\underline{r}, t)+S_{e x t}(\underline{r}), \\
\frac{1}{v_{2}} \frac{\partial \varphi_{2}(\underline{r}, t)}{\partial t}= & \nabla \cdot D_{2}(\underline{r}, t) \nabla \varphi_{2}(\underline{r}, t)-\Sigma_{a, 2}(\underline{r}, t) \varphi_{2}(\underline{r}, t) \\
& +\Sigma_{1} \rightarrow 2(\underline{r}, t) \varphi_{1}(\underline{r}, t), \\
\frac{\partial C_{k}(\underline{r}, t)}{\partial t}= & -\lambda_{k} C_{k}(\underline{r}, t)+\beta_{k} \sum_{g=1}^{2} v \Sigma_{f, g}(\underline{r}, t) \phi_{g}(\underline{r}, t) .
\end{aligned}
$$

The two-group space-time dependent diffusion equations are solved, in real time, in a 3D nodalization, with 157 radial nodes (one per fuel assembly) and 12 axial nodes per assembly (Figure 2), for neutron flux distribution. The nodalization was optimized to be able to complete the calculations in real time with 0.25 second time step, with consideration to maximize the spatial resolution to have the desired accuracy as defined in the ANSI/ANS-3.5-2009 [7] "Nuclear Power Plant Simulators for Use in Operator Training and Examination" standard.

The neutron cross sections and kinetic parameters in equations (1)-(3), from a specific fuel cycle of the referenced plant, were factored with control rod positions, moderator (water) temperature and density, fuel temperature, xenon and samarium number densities, and boron concentration. When performing the OLS calculations, the control rod positions, moderator temperature, and boron concentration are obtained from the KNS data. The xenon and samarium number densities and fuel temperature are calculated within the OLS model.

After solving the 3D matrices of equations (1) and (2) by alternate direction implicit (ADI) [8] method, the resulting two-group neutron flexes are then used to calculate the nodal fission heat, decay heat, xenon and samarium concentration, fuel temperature, and also the neutron detector signals of power ranges. In the OLS mode, the core model is calibrated with the KNS's power range readings. Discontinuity factors [9] are used on the diffusion constants of the two-group diffusion equations, equations (1) and (2), to 


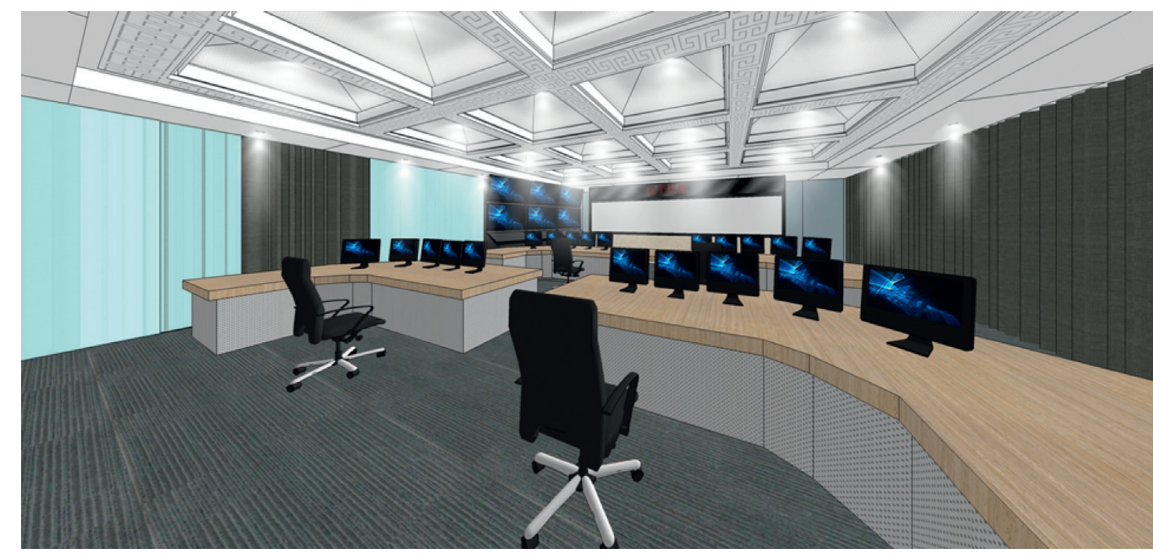

FIGURE 1: Control room mimic of digital I\&C validation real-time simulation platform.

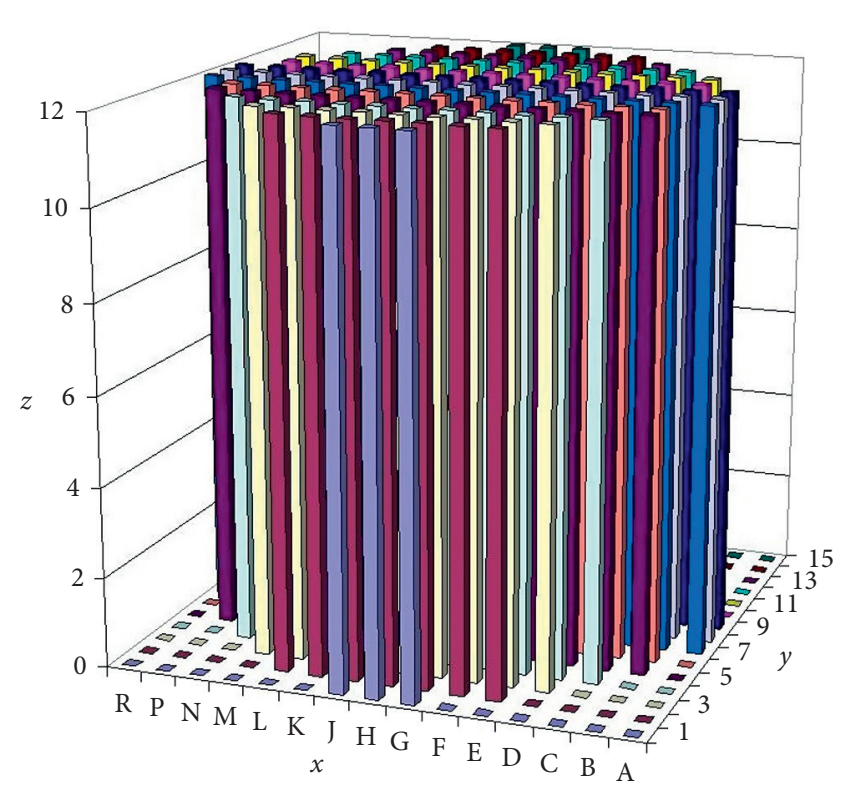

FIGURE 2: Reactor core simulation nodalization.

match the simulation power range signals with the KNS's measurement data.

2.2. Reactor/Steam Generator Flow Circuits. The reactor primary side and steam generator secondary side flow circuits are modeled with two phase, nonequilibrium, mass, momentum, and energy balance equations. A drift flux model is used to account for the interfacial velocity difference between the liquid and gas phases with consideration of counter current flow limitations (CCFL). The main thermal hydraulic equations solved in the model are [10] as follows:

Liquid Mass Conservation

$$
A \frac{\partial(1-\alpha) \rho_{\ell}}{\partial t}+\frac{\partial W_{\ell}}{\partial Z}=-A \Gamma+\delta_{s} S_{\ell}
$$

Vapor Mass Conservation

$$
A \frac{\partial\left(\alpha \rho_{v}\right)}{\partial t}+\frac{\partial W_{v}}{\partial Z}=A \Gamma+\delta_{s} S_{v} .
$$

Non-Condensable Gas Mass Conservation

$$
A \frac{\partial\left(\alpha \rho_{v}\right)}{\partial t}+\frac{\partial W_{n}}{\partial Z}=A \Gamma+\delta_{s} S_{v} .
$$

Mixture Energy Conservation

$$
A \frac{\partial(\rho h)}{\partial t}+\frac{\partial\left(W_{G} h_{G}+W_{L} h_{L}\right)}{\partial Z}=A\left(q_{w}^{\prime \prime \prime}+\frac{\partial p}{\partial t}\right)+\delta_{s} S h_{s} .
$$

\section{Gas Energy Conservation}

$$
\begin{aligned}
A \frac{\partial\left(\alpha \rho_{g} h_{g}\right)}{\partial t}+\frac{\partial\left(W_{g} h_{g}\right)}{\partial Z}= & A\left(\Gamma h_{v_{g a s}}+\Gamma_{n} h_{n}+q_{w g}^{\prime \prime \prime}-q_{g i}^{\prime \prime \prime}\right. \\
& +\alpha \frac{\partial p}{\partial t}+\delta_{S} S_{g} h_{s g} .
\end{aligned}
$$

Mixture Momentum Conservation Equation

$$
A \frac{\partial(\rho h)}{\partial t}+\frac{\partial\left(W_{G} h_{G}+W_{L} h_{L}\right)}{\partial Z}=A\left(q_{w}^{\prime \prime \prime}+\frac{\partial p}{\partial t}\right)+\delta_{s} S h_{s}
$$

Drift Flux Model

$$
V_{R}=\left(C_{o}-1\right) \frac{Q}{(1-\alpha) A}+\frac{\bar{V}_{g} j}{(1-\alpha)} .
$$

The above equation set is solved by a sparse matrix solver, in real time at 0.0125 second time step, with the nodalizations in Figures 3 and 4 for nodal thermal hydraulic properties. Again, the nodalization was the same as the RTS 


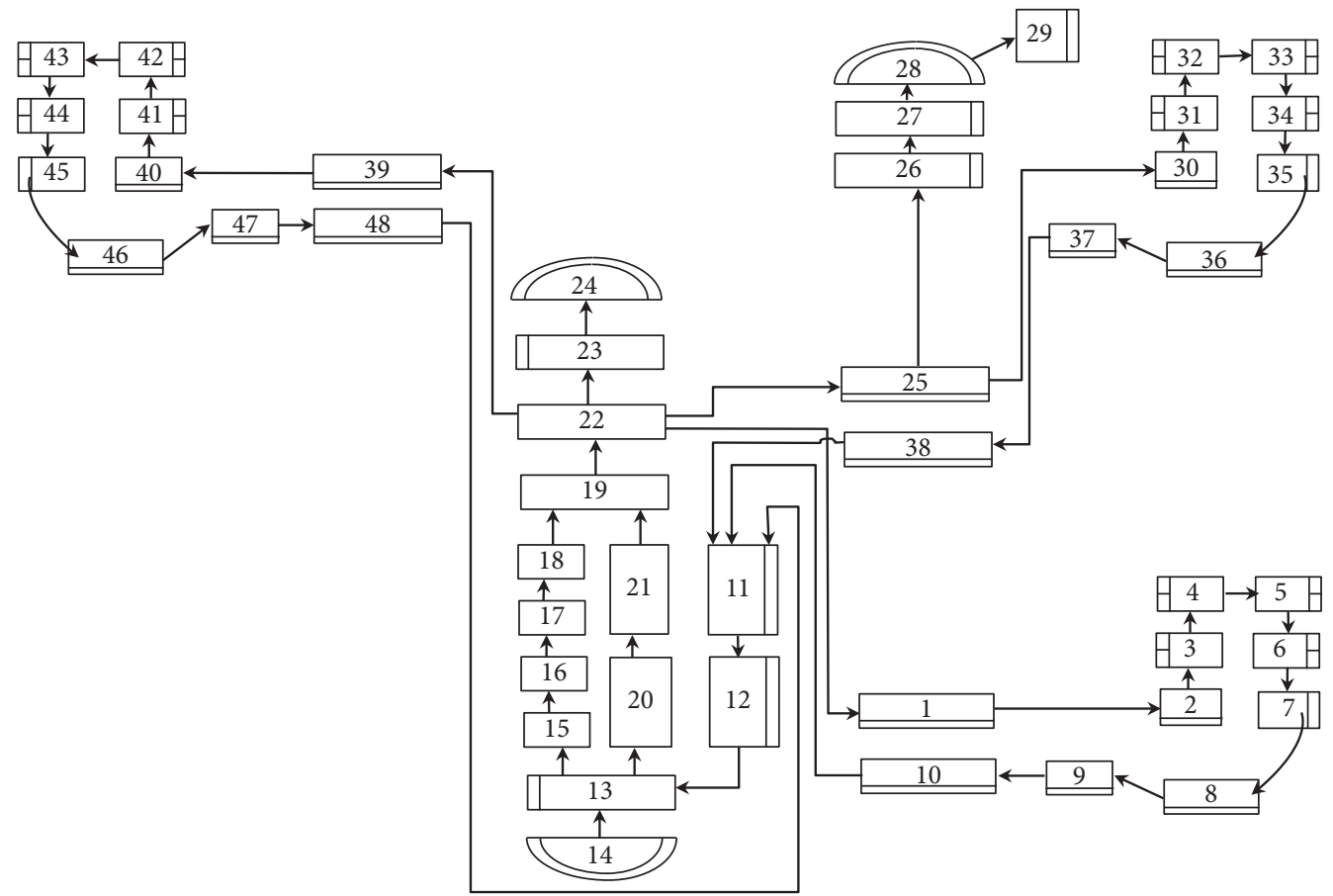

FIGURE 3: Reactor primary side flow circuit nodalization.

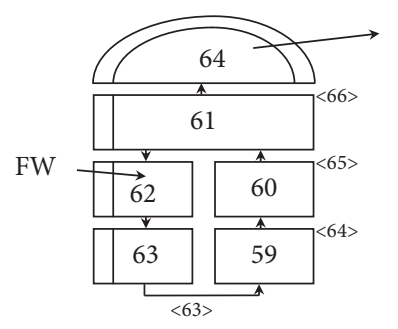

MS
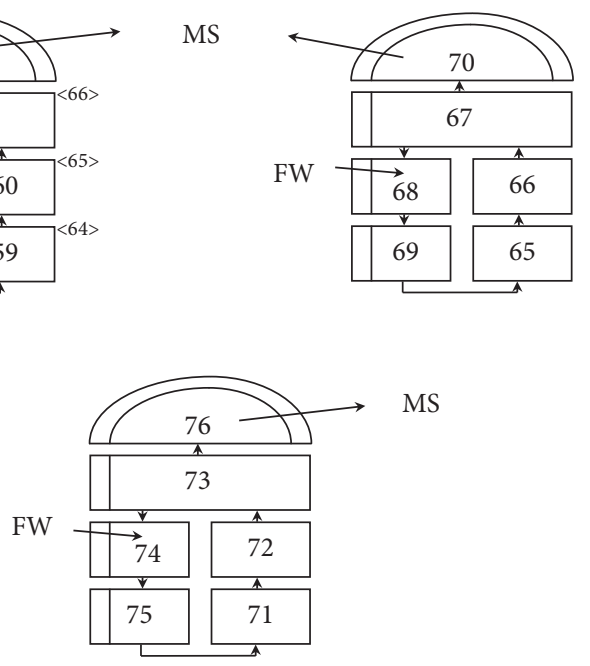

FIGURE 4: Steam generator secondary side flow circuit nodalization.

model to meet real-time computation constraint and satisfy accuracies required by ANSI/ANS-3.5-2009 standard.

The reactor circulation pump speeds on the primary side, main steam/feedwater/charging/letdown flows on the secondary side, and feedwater/charging temperatures on the secondary side are inputs, from KNS, to the two-phase thermal hydraulic model, and with core power distribution calculated in the simulation core model. When performing the OLS calculations, the calculated pressurizer and the steam generator pressures are calibrated against the KNS measurements. The pressurizer pressure control and the heat transfer between primary side and secondary side in the steam generators are used for calibration to match the calculated results with the measured data.

\section{Model Inputs and Outputs}

3.1. Inputs. The inputs to the OLS models, as boundary conditions and calibration data, are measurement data from the referenced plant KNS historical data, which include the following plant measurement data:

(i) Flows in and out of steam generators: main steam, feedwater, charging, and letdown

(ii) Temperatures of steam generator incoming flows: feedwater and charging

(iii) Temperatures of hot legs and cold legs

(iv) Temperatures of core exit thermal couples

(v) Reactor circulation pump speeds

(vi) Reactor core power/intermediate/source ranges

(vii) Control rod positions

(viii) Boron concentration

3.2. Outputs. The outputs from the simulation models, for comparisons with the corresponding plant measurements to validate the OLS models, are the following:

(i) Reactor thermal power

(ii) Pressurizer pressure, level, and temperature

(iii) Reactor average temperature

(iv) Steam generator pressure and level

\section{Results}

The OLS simulation models were ran in real time, with connection to the KNS system, which monitors the reference 


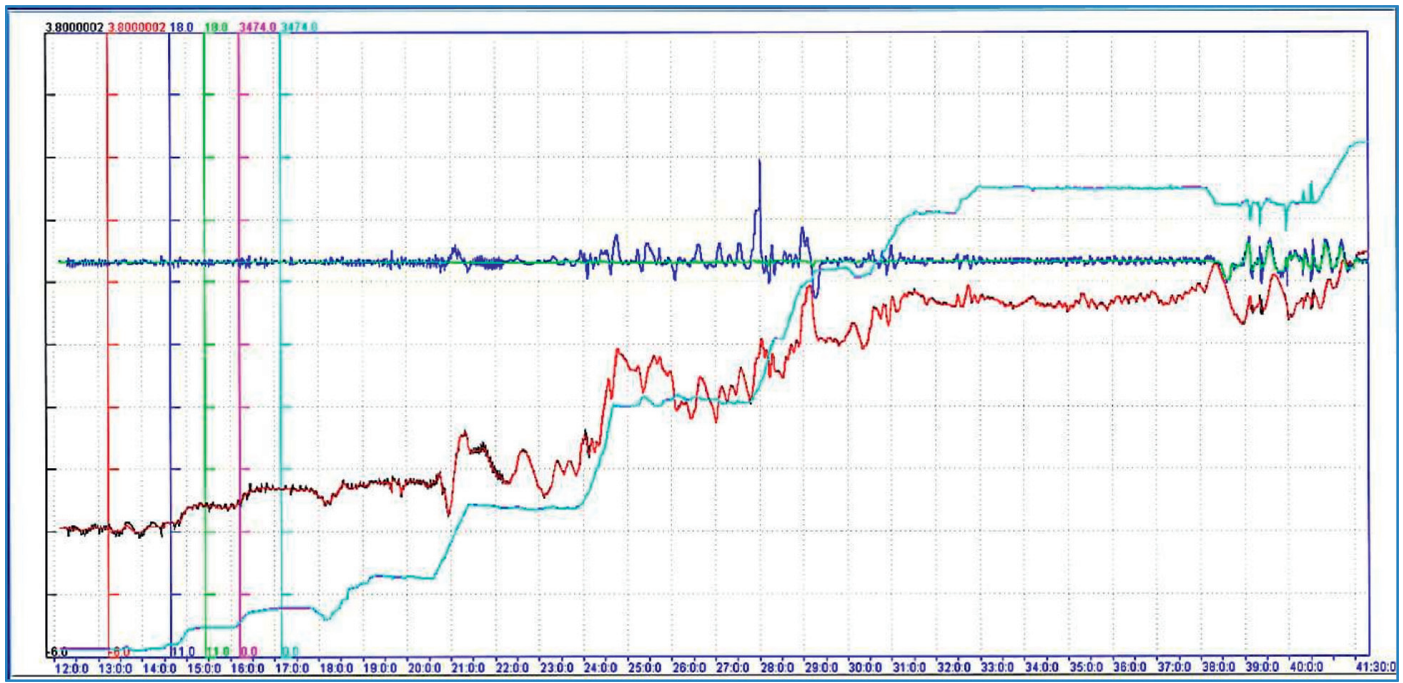

Figure 5: Power up operation-power, pressure, and level. Reactor thermal power (magenta \& cyan), range: 0 3474 MW; pressurizer pressure (blue \& green), range: $11 \sim 18 \mathrm{MPa}$; pressurizer level (black \& red), range: $-6 \sim 3.8 \mathrm{~m}$.

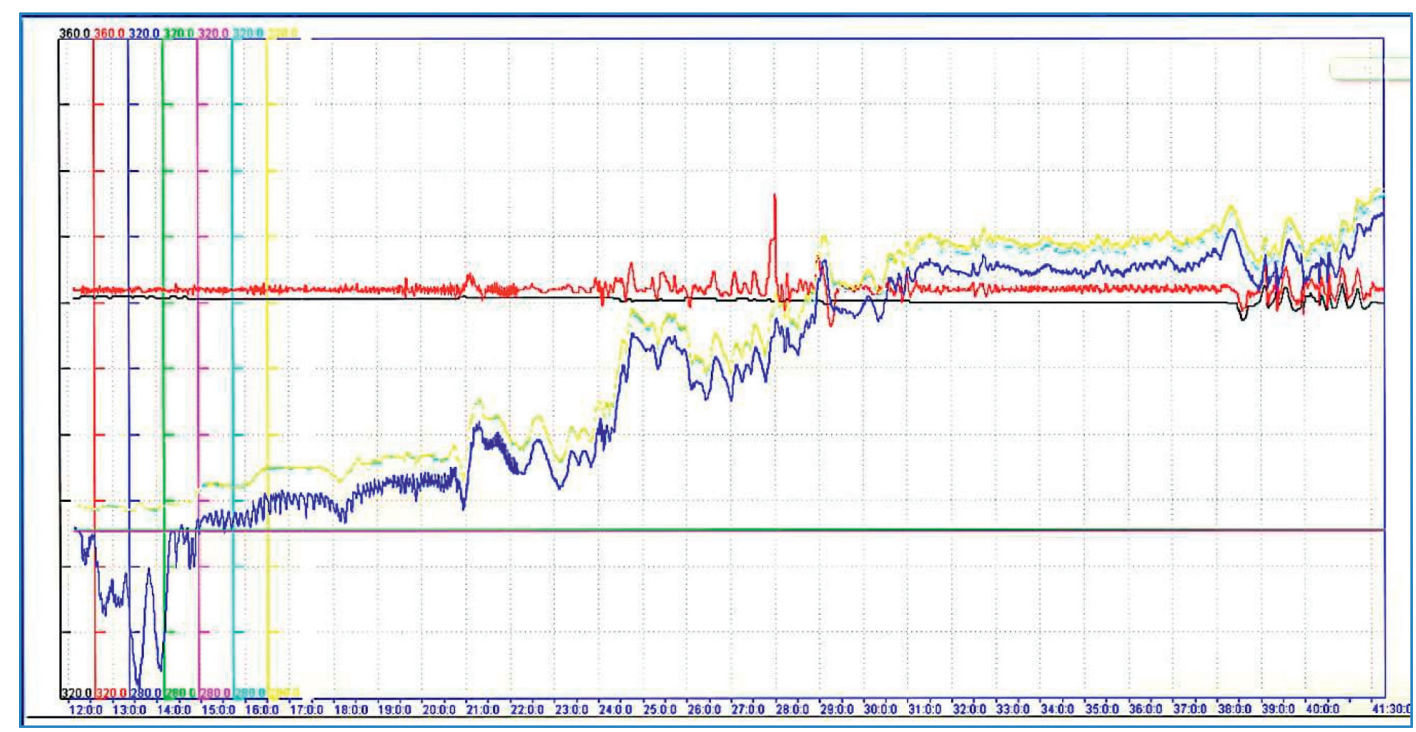

Figure 6: Power up operation-temperatures. Pressurizer steam space temperature (black \& red), range: $320 \sim 360^{\circ} \mathrm{C}$; Reactor circulation loop average temperatures (blue, green, magenta \& cyan, orange, white), range: $280 \sim 320^{\circ} \mathrm{C}$.

plant operation. Three recorded plant operation events from KNS were used to validate the OLS models:
(i) Power up operation
(ii) Power maneuvering
(iii) Steam generator level transient

The comparisons of key parameters are presented for each event from the RTS instructor station's trend plot screens, with color noted for results from KNS measurements and OLS models (color A \& color B). The color(s) on the left of " $\&$ " are KNS measurements from the recorded event, and the color(s) on the right of " $\&$ " are the OLS model results in real time, and the ranges of the parameters are noted after the line color notation.
4.1. Power up Operation. The reactor was started up with power increased from zero to full power over a 36-hour period. Figures 5-8 present the comparisons of the key parameters during this event with the parameters noted under each figure's caption. The $X$-axis is the time for the event for 36 hours. The deviation of OLS results from the recorded KNS data was less than $10 \%$, which satisfied the requirements of ANSI/ANS-3.5-2009 standard and the plant operation procedure acceptance criteria.

4.2. Power Maneuvering. The reactor power started from $80 \%$ to $50 \%$ in 2 hours and stayed at $50 \%$ for 1 hour and then increased to $100 \%$ in 2 hours. Figures 9-12 present the comparisons of the key parameters during this event with 


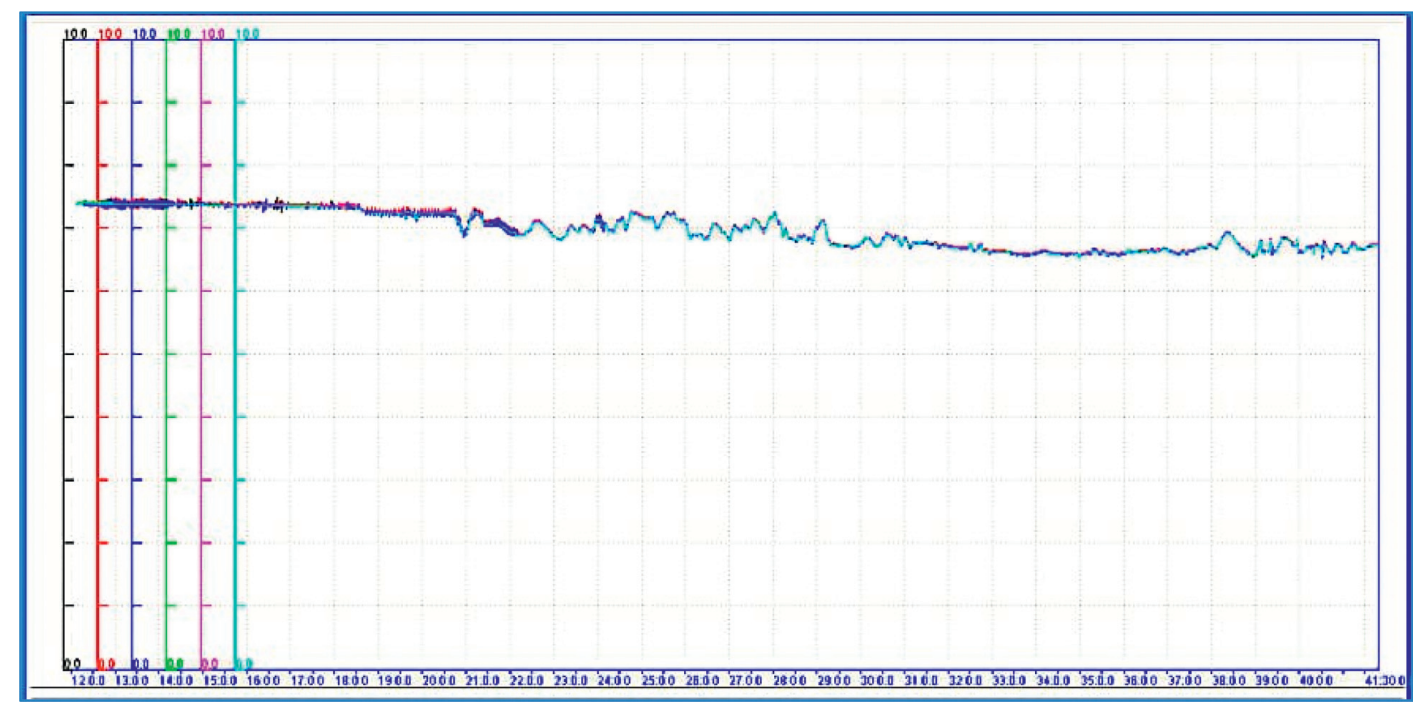

Figure 7: Power up operation-pressures. Steam generator pressures (black, red, blue \& green, magenta, cyan), range: 0 10 MPa.

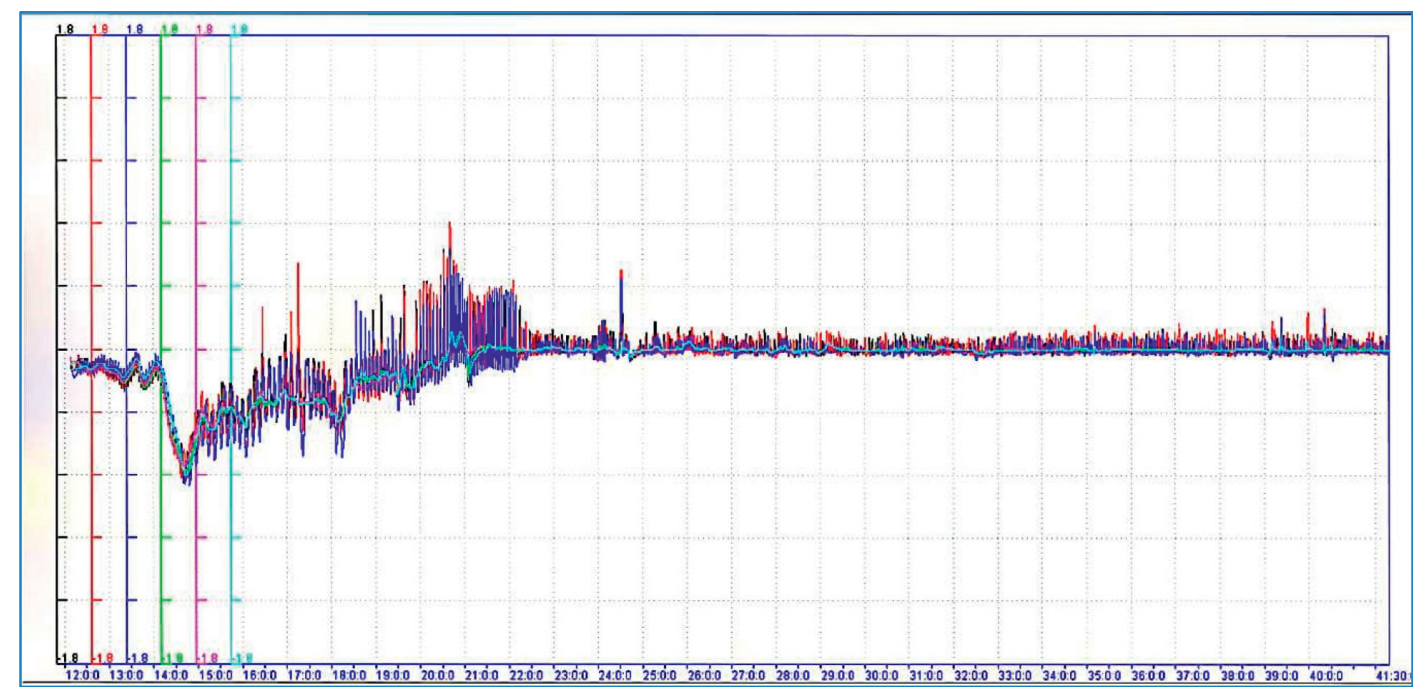

Figure 8: Power up operation-levels. Steam generator levels (black, red, blue \& green, magenta, cyan), range: $-1.8 \sim 1.8 \mathrm{~m}$.

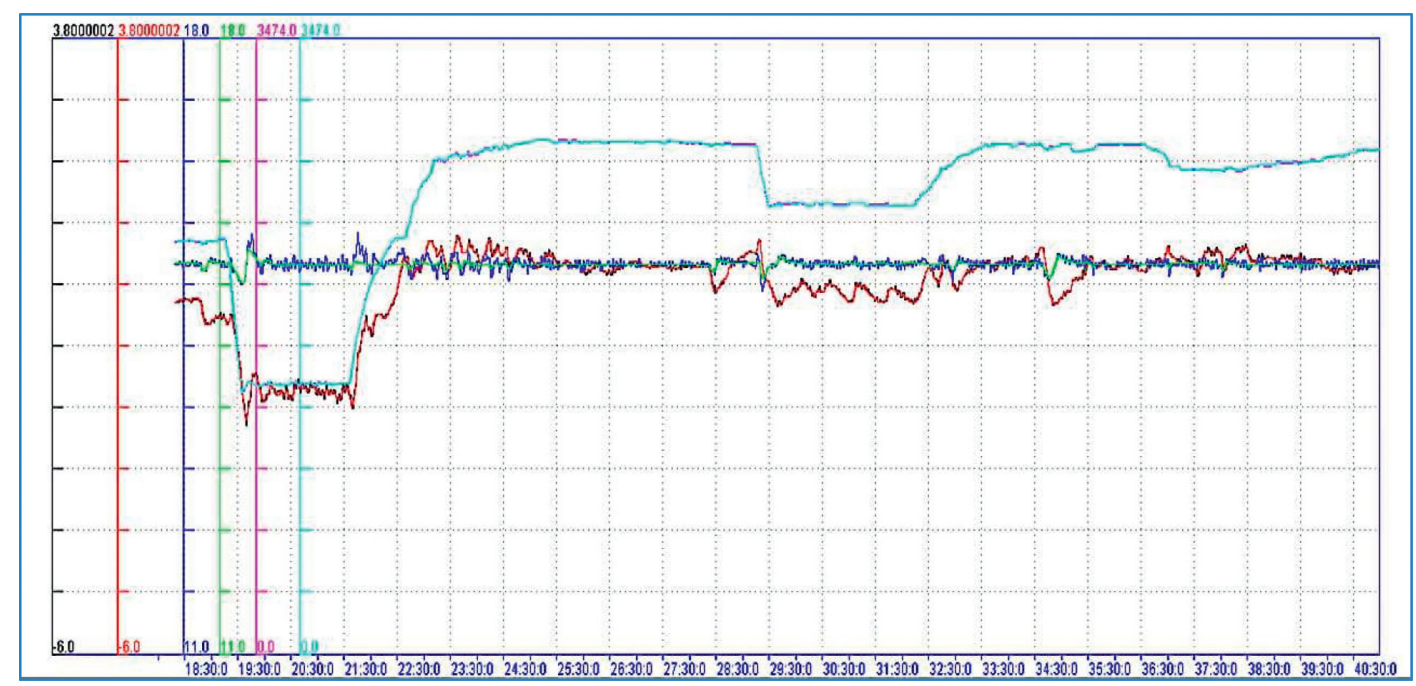

Figure 9: Power maneuvering-power, pressure, and level. Reactor thermal power (magenta \& cyan), range: 0 3474 MW; pressurizer pressure (blue \& green), range: 11 18 MPa; pressurizer level (black \& red), range: $-6 \sim 3.8 \mathrm{~m}$. 


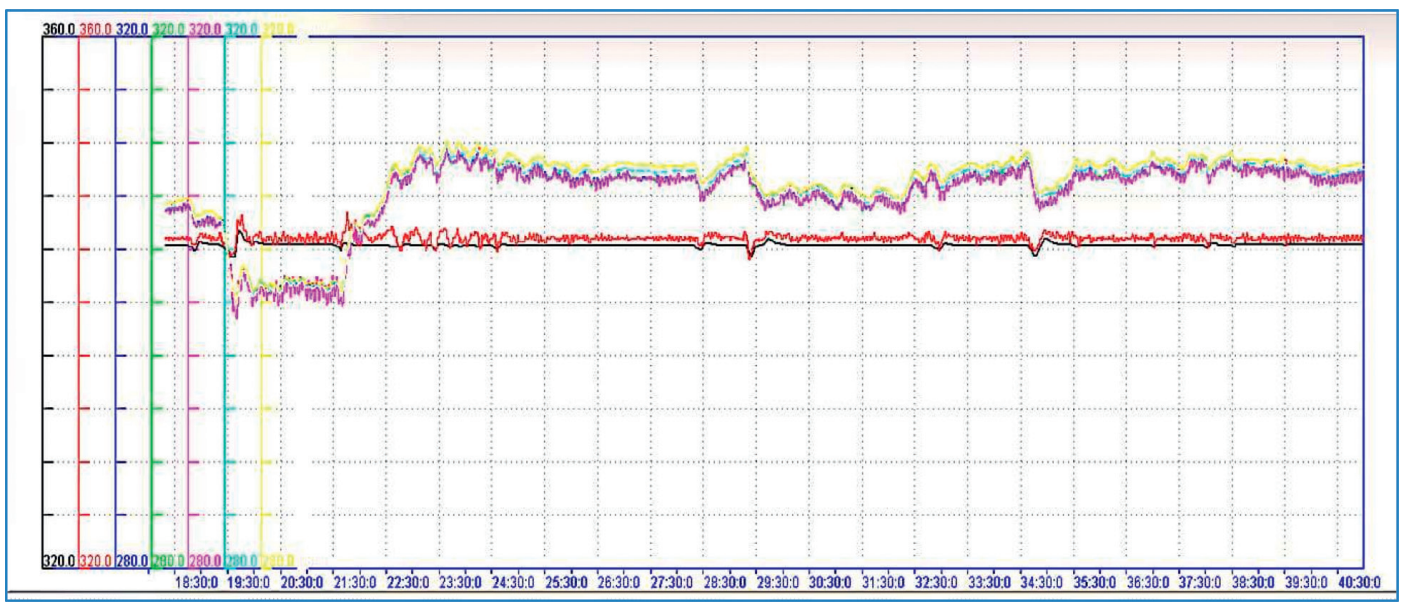

Figure 10: Power maneuvering-temperatures. Pressurizer steam space temperature (black \& red), range: $320 \sim 360^{\circ} \mathrm{C}$; reactor circulation loop average temperatures (blue, green, magenta \& cyan, orange, white), range: $280 \sim 320^{\circ} \mathrm{C}$.

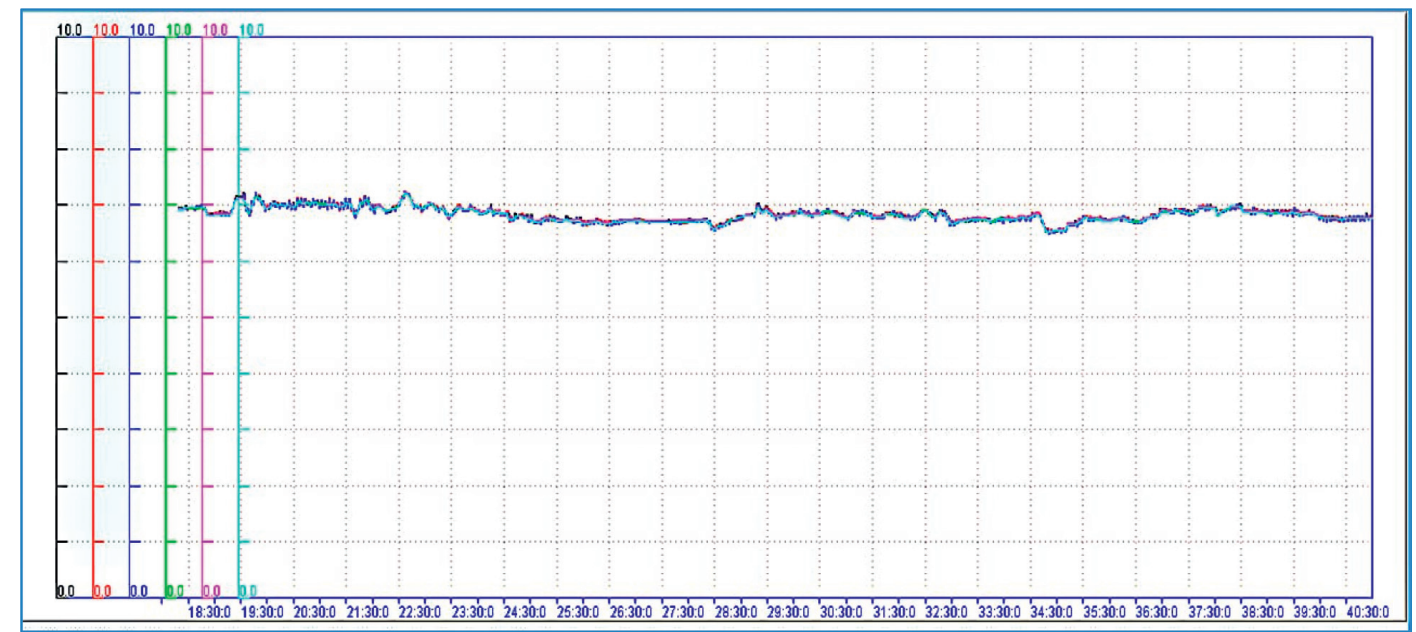

Figure 11: Power maneuvering-pressures. Steam generator pressures (black, red, blue \& green, magenta, cyan), range: 0 10 MPa.

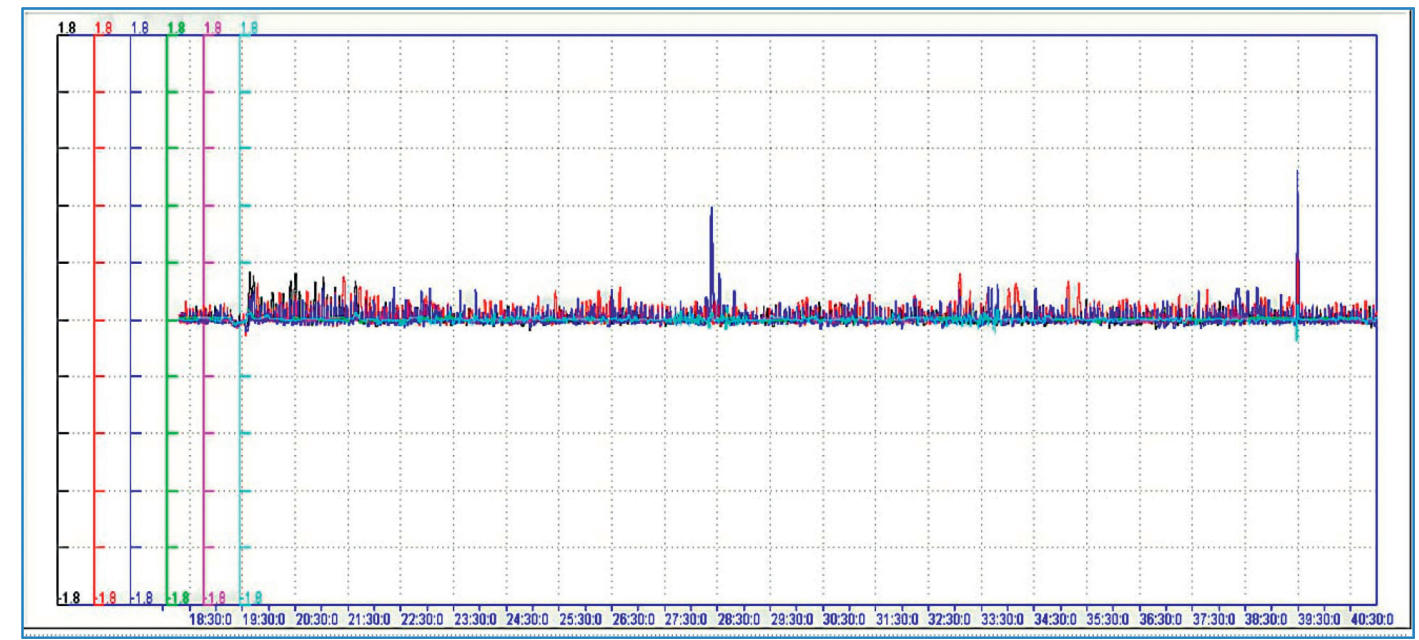

Figure 12: Power maneuvering-levels. Steam generator levels (black, red, blue \& green, magenta, cyan), range: $-1.8 \sim 1.8 \mathrm{~m}$. 


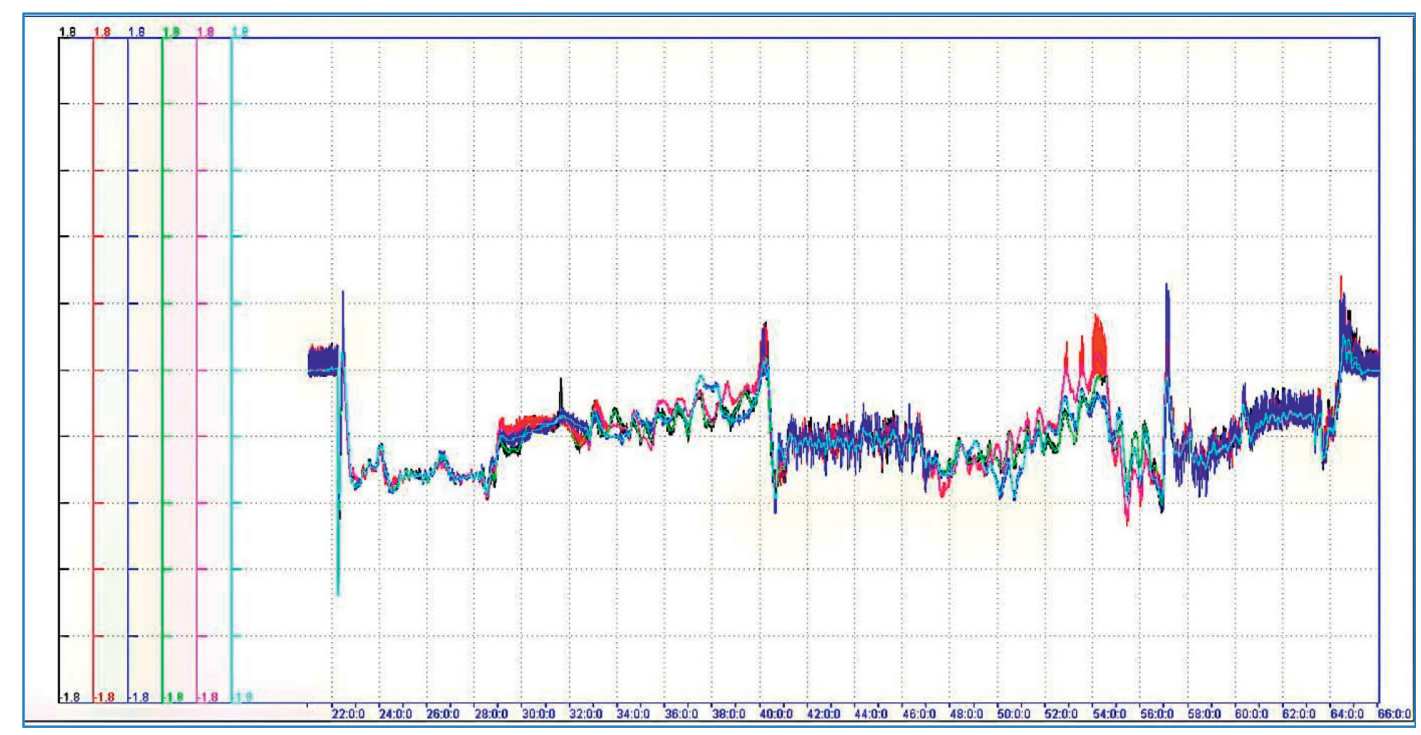

Figure 13: Steam generator level transient-levels. Steam generator levels (black, red, blue \& green, magenta, cyan), range: $-1.8 \sim 1.8 \mathrm{~m}$.

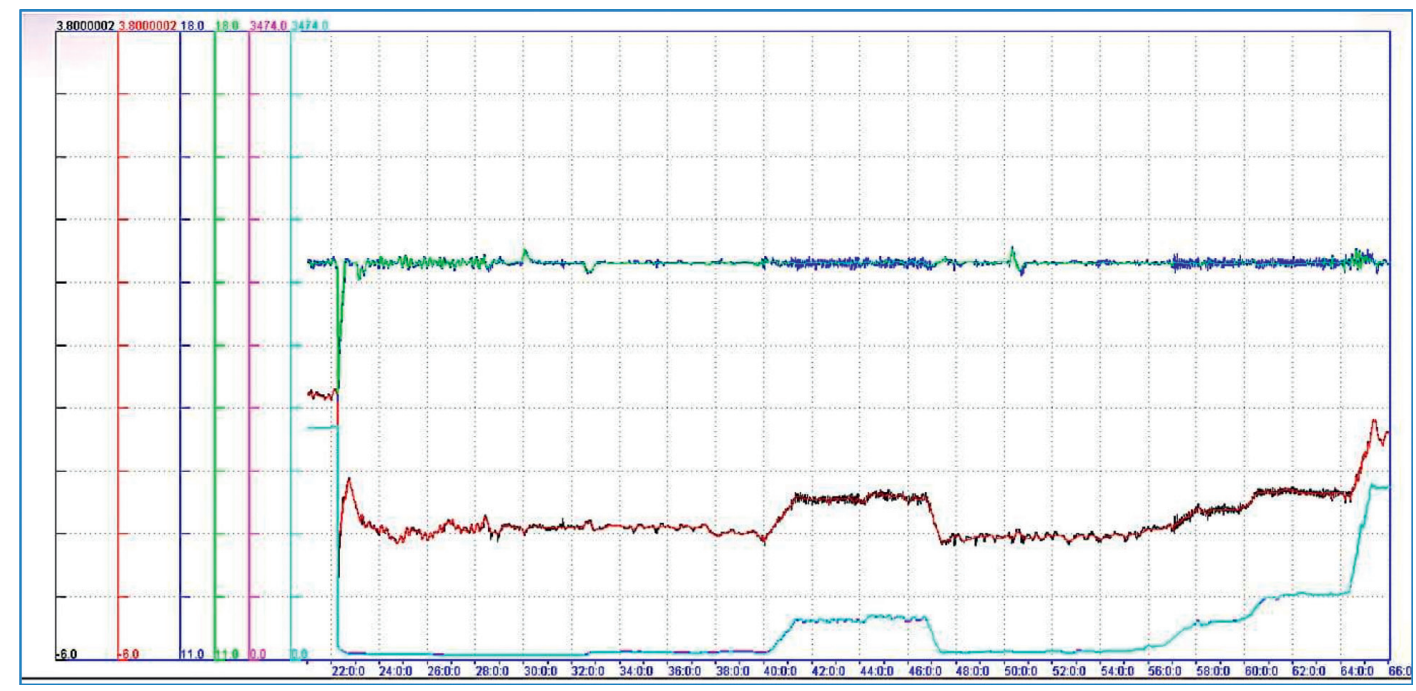

FiguRE 14: Steam generator level transient-power, pressure, and level. Reactor thermal power (magenta \& cyan), range: 0 3474 MW; pressurizer pressure (blue \& green), range: $11 \sim 18 \mathrm{MPa}$; pressurizer level (black \& red), range: $-6 \sim 3.8 \mathrm{~m}$.

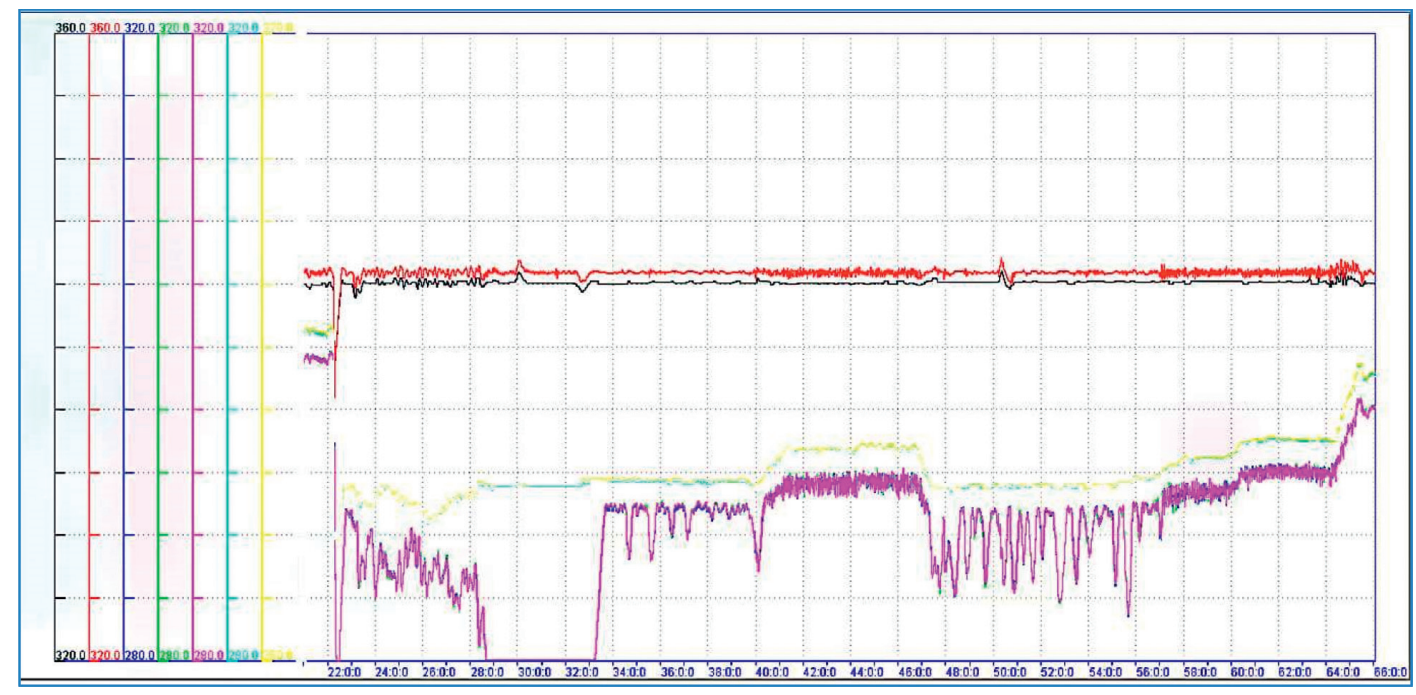

FiguRE 15: Steam generator level transient-temperatures. Pressurizer steam space temperature (black \& red), range: $320 \sim 360^{\circ} \mathrm{C}$; reactor circulation loop average temperatures (blue, green, magenta \& cyan, orange, white), range: $280 \sim 320^{\circ} \mathrm{C}$. 


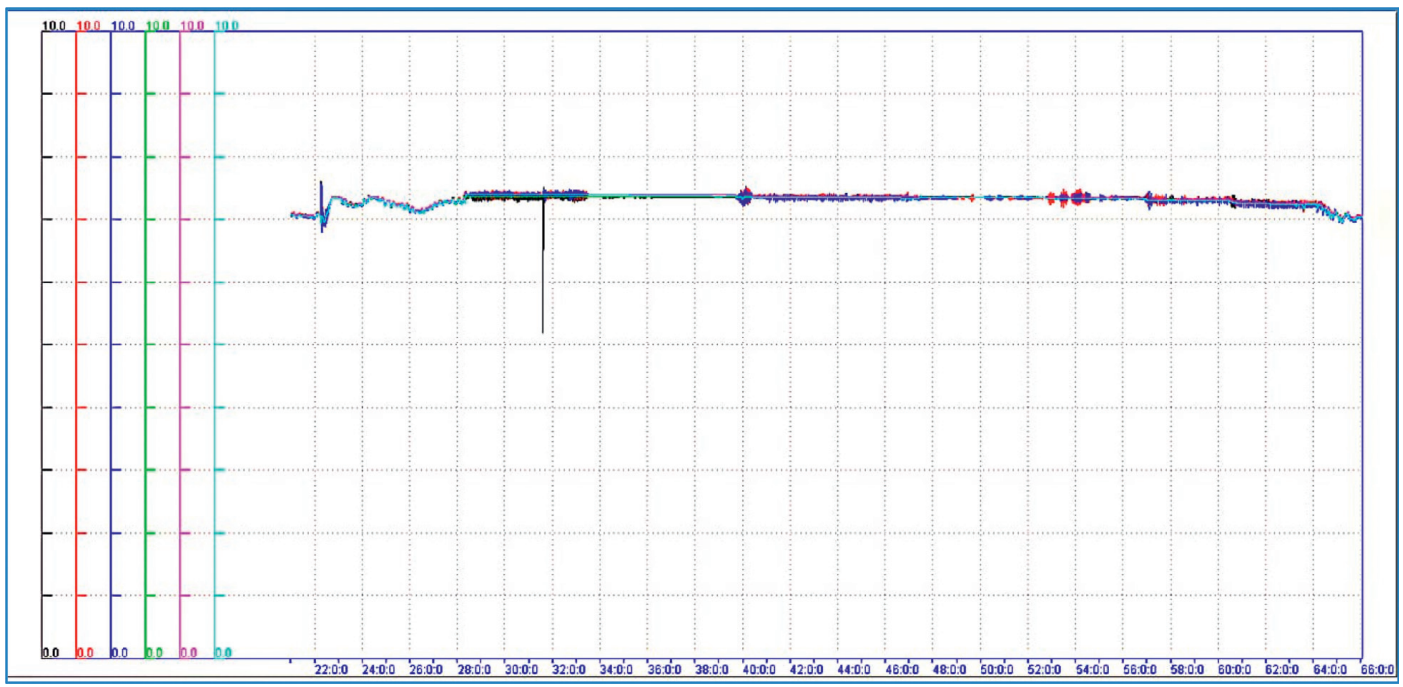

FiguRE 16: Steam generator level transient-pressures. Steam generator pressures (black, red, blue \& green, magenta, cyan), range: $0 \sim 10 \mathrm{MPa}$.

the parameters noted under each figure's caption. The $X$-axis is the time for the event for 24 hours. The deviation of OLS results from the recorded KNS data was less than $10 \%$, which satisfied the requirements of ANSI/ANS-3.5-2009 standard and the plant operation procedure acceptance criteria.

4.3. Steam Generator Level Transient. The steam generator level went to low level due to malfunctioning of control valves and caused ensuing reactor trip, and then reactor was started up again with unstable steam generator level over a 45-hour period. Figures 13-16 present the comparisons of the key parameters during this event with the parameters noted under each figure's caption. The $X$-axis is the time for the event for 45 hours. The deviation of OLS results from the recorded KNS data was less than $10 \%$, which satisfied the requirements of ANSI/ANS-3.5-2009 standard and the plant operation procedure acceptance criteria.

\section{Conclusion}

As shown in Figures 5-16, the comparisons between the results of OLS simulation models and the corresponding KNS measurement data are in very good agreements, both in timing and in magnitude, for the three plant operation events being studied. The good agreements provided validation of the adequacy and accuracy of the simulation models.

The works presented here is the first stage of applying OLS to support plant operations. The validated models will be the base to develop fault detection and prevention system for plant operators to enhance plant safety and efficiency.

\section{Data Availability}

The data used in this paper is part of the plant operation data, which is proprietary and cannot be disclosed.

\section{Conflicts of Interest}

The authors declare that they have no conflicts of interest.

\section{Acknowledgments}

This work was supported in part by the Guangdong Basic and Applied Basic Research Foundation (project no. 2019B1515120060) and in part by the Open Funds of State Key Laboratory of Nuclear Power Safety Monitoring Technology and Equipment.

\section{References}

[1] Z. Ma, "Application of on-line simulation Technology in Yimin power plant," in Proceedings of the 8th Annual Meeting of National Thermal Power Unit (600MW) Competition, pp. 2004344-2004348, New York, NY, USA, 2004.

[2] D. Chang and S. Wang, "Development of pipeline simulation Technology abroad," Oil and Gas Storage and Transportation, vol. 16, no. 10, pp. 9-13, 1997.

[3] F. Chou, "Online transient behavior prediction in nuclear power plants," Applied Artificial Intelligence, vol. 2000, no. 14, pp. 967-1001, 2000.

[4] Westinghouse Electric Company, Beacon Core Monitoring System, General Technical Description, Berlin, Germany, 2014.

[5] A. Dall'Osso, A Method to Reset a 3D on Line Core Model on Incore Measurements, PHYSOR, Seoul, South Korea, 2002.

[6] GSE Systems, Inc, "REMARK modelling techniques handbook," 2008.

[7] American Nuclear Society, Nuclear Power Plant Simulators for Use in Operator Training and Examination, ANSI/ANS-3, Berlin, Germany, 2009.

[8] V. Simoncini, "Computational methods for linear matrix equations," SIAM Review, vol. 58, no. 3, pp. 377-441, 2016.

[9] Argonne Nation Laboratory, DIF3D: A Code to Solve One-, Two-, and Three-Dimensional Finite-Difference Diffusion Theory Problems, ANL, London, UK, 1982.

[10] GSE Systems, Inc, "RETACT modelling techniques handbook for PWR,” 2005. 